\title{
Research on New Energy and Traditional Energy Based on SPSS
}

\author{
Yue Liu ${ }^{1} \&$ Jingqiu $\mathrm{Wu}^{1}$ \\ ${ }^{1}$ Nanjing University of Aeronautics and Astronautics, Nanjing, China \\ Correspondence: Yue Liu, Postgraduate student, Nanjing University of Aeronautics and Astronautics, Nanjing, \\ China. E-mail: 691706687@qq.com
}

Received: December 7, 2016

Accepted: January 5, 2017

Online Published: January 20, 2017

doi:10.5539/ijef.v9n2p189

URL: http://dx.doi.org/10.5539/ijef.v9n2p189

\begin{abstract}
In China, the main profit of the energy industry is traditional energy sources, the proportion of traditional energy companies take on a high number. However, China has been putting forward green economy, with strongly support of national policy, the new energy enterprises emerge in an endlessly stream, the businesses involved in new energy economy profit a lot and that everyone is better off, which leads to a relatively strong upward tendency for new energy stocks. Therefore, based on such a fierce competition in the energy industry, it is necessary to know if the relevance of the new energy stock and traditional energy stock is positive or negative. This thesis is based on a combination of correlation analysis and regression analysis, analyze the correlation of new energy stock and traditional energy stock, and the sub-sectors of new energy, do research on stock investment strategy through the analysis of convergence. We firstly use SPSS to carry out correlation analysis on stock price, quantitatively illustrate the relationship between the two kinds of stocks, and then calculate the correlation coefficient, determine its correlation strength, at last linear regression analysis by SPSS, and summarize a functional relationship for the stock.
\end{abstract}

Keywords: SPSS, new energy stock, traditional energy stock, stock investment

\section{Introduction}

New energy industry is now a strategic industry in China, which has been springing up in recent years. The proposal of the Thirteenth Five Year Plan one again pushes the new energy industry to a new high, and new energy industry comes to a new stage of development. So based on current situation, it is necessary to carry research on the new energy industry another step forward. The proposal of the Thirteenth Five Year Plan is a symbol, it sends a message that China is in the transition period of energy industry development, from now on China will deeply focus on the healthy development of new and renewable energy industry, such as the exploitation and utilization of solar energy and wind energy, so as to strive to achieve leap-type transformation of the new energy industry in all aspects during the period of the Thirteenth Five Year Plan, to enhance the professional standards in the field of system and technology. At the same time, the State Council issued a plan of energy strategic development, by the end of the Thirteenth Five Year Plan, we expect that in the use of energy consumption, the proportion of new energy can get a substantial increase, and the specific goal is by the end of 2020 , the proportion of non fossil energy account for primary energy consumption will increase to $15 \%$, the positioning of renewable energy will be transformed from supplements into replacement, the State investment for new energy is expected to be more than 300 billion yuan. On the basis of the strong support from national policy, the development of the new energy industry is bound to be very powerful.

In the energy industry, the main source of profit comes from traditional energy industry, however, the profitability of new energy has been strengthened, and the exploitation and utilization of new energy has caused wide public concern. With the strong policy support, new energy enterprises emerge in endlessly, new energy company's shares also present a relatively strong rise, which cause a lot of hot issues and attract more and more attention of the energy field. Therefore, based on such a fierce competition in the energy industry, it is necessary to know if the relevance of the new energy stock and traditional energy stock is positive or negative, and the research of the relevance of new energy stocks and traditional energy stocks has important theoretical and practical significance.

During the development of new energy enterprises, external policy, technology and many other kinds of factors can easily affect the progress of the company's management and development. The market share of wind, solar, 
nuclear and other new energy enterprises is different, so the market competition circumstance is different, and the company's stock performance in the market is also not the same. For the purpose of the practical significance of research and conclusion, it is necessary to select some representative company from various kinds of new energy, comparatively analyze according to the company's stock prices so as to drew the conclusion of that there exists the correlativity between the sectors of new energy.

\section{Concepts of Correlation and Regression Analysis}

Stock market is a barometer of the economic development in China, the stock market has become the main factors for us to get a reference of economic development, so the research of the stock market is a hot topic in the field of economics. On the other hand, the recent researches of many scholars focus on the overall stock market price prediction and empirical study, which are lack of systematic analysis of individual industry and lack of an inaccurate understanding of the industry characteristics and development trend. This thesis is on the base of the stock quotations tendency of some representative companies in new energy industry and traditional energy industry, we proceed to do the correlation analysis and regression analysis by SPSS, then carry out the data analysis on the stock price fluctuation trend of new energy and traditional energy, finally we sum up a function relation and positive and negative correlation between these two, which give the answer to stock investment strategy.

The correlation analysis is to use a certain amount of sample data, get the variables from two kinds of the sample data, and then conduct the analysis of the degree of linear correlation between variables, at last manifest the linear correlation as converging relation of two variables. The correlation analysis generally has three steps: first, put forward the hypothetical judgment of linear correlation between two variables; secondly, draw a simple scatter diagram using software, roughly present the converging relation through the variable distribution situation of each point; Thirdly, accurately calculate the coefficient of the linear relationship between the two variables through software. The most common factor in the correlation analysis is the Pearson Correlation Coefficient, the formula is shown as the following:

$$
\mathrm{r}=\frac{\sum(X-\bar{X})(Y-\bar{Y})}{\left(\sqrt{\sum_{\mathrm{i}=1}^{\mathrm{n}}\left(X_{\mathrm{i}}-\bar{X}\right)^{2}}\right)\left(\sqrt{\sum_{\mathrm{i}=1}^{\mathrm{n}}\left(Y_{\mathrm{i}}-\bar{Y}\right)^{2}}\right)}
$$

According to the number of the Pearson correlation coefficient $\mathrm{r}$, the linear correlation between variables can be divided into four levels: $0.8<|\mathrm{r}| \leq 1$ means highly relevant; $0.5<|\mathrm{r}| \leq 0.8$ means middling relevant; $0.3<|\mathrm{r}| \leq 0.5$ means low grade relevant; $0<|\mathrm{r}| \leq 0.3$ means weakly relevant.

Regression analysis is based on a certain amount of sample data, choose the independent variable and dependent variable from the sample data, and then come to a conclusion of the regression relations between the independent variable and dependent variable by means of a series of mathematical statistics methods. In general regression analysis can be divided into four steps: first step is to determine the independent variable and dependent variable; secondly, make sure of the mathematical relationship based on the samples; the third step is to determine the parameters of the regression equation, and then verify that the checksum matches; the final step is to estimate and forecast by using regression equation.

\section{Stock Investment Algorithm Basic Thoughts}

This thesis is to realize the stock investment analysis mainly by means of the statistical analysis of stock price, which is known as the method of correlation and regression analysis. The correlation between two stock prices often manifest as the fluctuation of one stock can have obvious influence on the price of another kind of stock, if the influence does exist, it indicate there are convergence and association between these two. The association between the two stocks can be expressed by concrete numerical value. From Pearson coefficient formula, we can get the correlation coefficient between the variable is $\mathrm{r}$, the stock price of the two variables is $\mathrm{X}, \mathrm{Y}$, the function relational expression is $Y=\beta_{0}+\beta_{1} X$, in which $\beta_{I}$ is constant, $\beta_{I}$ stands for the regression coefficients of $\mathrm{X}$ and Y.

\section{Empirical Analysis}

\subsection{Analysis of the Correlation between New Energy and Conventional Energy}

\subsubsection{Import the Stock History Data}

We use the "Tong Hua Shun" software to derive the stocks history data of the two representatives in the new energy industry and traditional energy industry. In this thesis, we take "TOPRAYSOLAR" and "Shanxi Coal and 
Chemical Industry" as examples, the two stocks are selected the quarterly closing price from 1th January 2014 to 31th March 2016, and then consolidate it to the form of Excel to import into SPSS, in which the date, closing price and the residual error must be included.

Table 1. The stocks history data of "TOPRAYSOLAR" and "Shanxi coal and chemical industry"

\begin{tabular}{ccc}
\hline Date & TOPRAYSOLAR closing price & Shanxi Coal and Chemical Industry closing price \\
\hline the First quarter of 2016 & 8.87 & 4.38 \\
the Forth quarter of 2015 & 10.99 & 4.86 \\
the Third quarter of 2015 & 7.92 & 4.42 \\
the Second quarter of 2015 & 12.78 & 8.18 \\
the First quarter of 2015 & 13.23 & 8.16 \\
the Forth quarter of 2014 & 9.34 & 6.65 \\
the Third quarter of 2014 & 11.49 & 5.72 \\
the Second quarter of 2014 & 9.99 & 4.13 \\
the First quarter of 2014 & 9.72 & 4.1 \\
\hline
\end{tabular}

\subsubsection{The Correlation Analysis}

We use SPSS software to carry on the "TOPRAYSOLAR" and "Shanxi Coal and Chemical Industry" correlation analysis. But before jumping ahead into correlation analysis, first of all we need to make a scatter plot between the two variables, judging whether it has linear relation between the two from the subjective, as shown in Figure 1.

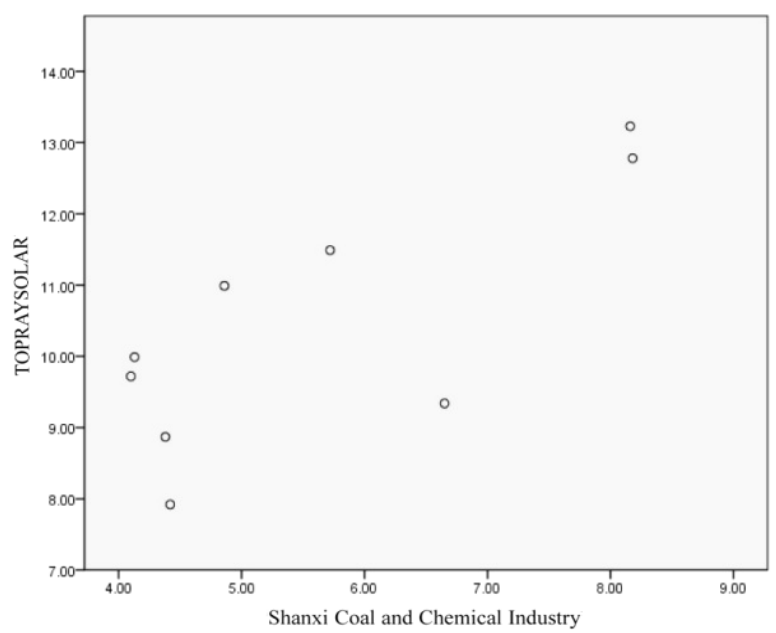

Figure 1. Scatter plot between the two variables

The Figure 1 shows there is a certain relationship between the two variables,In particular with the increase of "Shanxi Coal and Chemical Industry" stock price, the price of "TOPRAYSOLAR" is also increasing, however, as to how relevant one stock is to the other, judging from subjective can not be absolute correct, so we need to take things to a next level to calculate the correlation coefficient between "Shanxi Coal and Chemical Industry" and "TOPRAYSOLAR", to determine the correlation degree between the two variables.

The calculated correlation coefficient and inspection is as shown in Table 2.

Table 2. Pearson correlation coefficients

\begin{tabular}{cccc}
\hline & & TOPRAYSOLAR & Shanxi Coal and Chemical Industry \\
\hline & Pearson correlation coefficients & 1 & $0.774^{*}$ \\
TOPRAYSOLAR & Statistical significance & & 0.014 \\
& $\mathrm{~N}$ & 9 & 9 \\
Shanxi Coal and Chemical & Pearson correlation coefficients & $0.774^{*}$ & 1 \\
Industry & Statistical significance & 0.014 & 9 \\
\hline
\end{tabular}

*. Significant correlation at level 0.05 . 
From Table 2, we can get that the Pearson correlation coefficient between "Shanxi Coal and Chemical Industry" and "TOPRAYSOLAR" is 0.774 , which means a positive correlation between the two stock, as one stock price growing, the other one grows with it. As we can see from the $\mathrm{P}$ value of the significance test results, $\mathrm{P}$ value is 0.014 , clearly less than 0.05 , under the circumstances of $5 \%$ significance level, the two variables pass the test of significance,therefore, it proves a positive linear relationship between the two stock, with a highly related degree. On the basis of this, we continue to use the regression analysis to move forward a single step.

\subsubsection{The Regression Analysis}

To reinforce the stock price change of "TOPRAYSOLAR", to find out how it affected by other factors, "TOPRAYSOLAR" is defined as the dependent variable (y), while "Shanxi Coal and Chemical Industry" is defined as the independent variable (x), establishing the linear regression model of one-variable between the two.

Table 3. Model summary

\begin{tabular}{cccccc}
\hline Model & $\mathrm{R}$ & $\mathrm{R}$ square & Adjusted R square & standard error of estimate & Durbin-Watson \\
\hline 1 & $0.774^{\mathrm{a}}$ & 0.599 & 0.542 & 1.20567 & 2.653 \\
\hline
\end{tabular}

a. Independent variable:Shanxi Coal and Chemical Industry.

b. Dependent variable:TOPRAYSOLAR

The Table 3 shows that $\mathrm{R}$ square value is 0.599 , the adjusted $\mathrm{R}$ square is 0.542 , meaning the degree of fitting for the model is $59.9 \%$, the adjusted degree of fitting for the model is $54.2 \%$, illustrating the model fitting is relatively good to a certain extent .

Table 4. Analysis of variance

\begin{tabular}{clccccc}
\hline & Model & Sum of Squares & df & Mean square & F & Sig. \\
\hline \multirow{2}{*}{1} & Regression & 15.220 & 1 & 15.220 & 10.470 & $0.014 \mathrm{~b}$ \\
& Residual error & 10.176 & 7 & 1.454 & & \\
& Final tota & 25.396 & 8 & & & \\
\hline
\end{tabular}

a. Dependent variable:TOPRAYSOLAR.

b. Independent variable:Shanxi Coal and Chemical Industry.

Table 4 is the test results of variance analysis for the model significance, what can be seen from the table is that the $\mathrm{F}$ statistic value is 10.470 , the corresponding $\mathrm{P}$ value is 0.014 , which is less than 0.05 , under the circumstance of $5 \%$ significance level, the model passes the significance test.

Table 5. Estimation on varying coeffcient models

\begin{tabular}{|c|c|c|c|c|c|c|}
\hline & \multirow{2}{*}{ Model } & \multicolumn{2}{|c|}{ Unstandardized Coefficients } & \multirow{2}{*}{$\begin{array}{c}\text { Standardized Coefficients } \\
\text { Beta }\end{array}$} & \multirow{2}{*}{$\mathrm{t}$} & \multirow{2}{*}{ Sig. } \\
\hline & & $\mathrm{B}$ & Standard error & & & \\
\hline \multirow{2}{*}{1} & (Constant) & 5.822 & 1.495 & & 3.894 & 0.006 \\
\hline & TOPRAYSOLAR & 0.829 & 0.256 & 0.774 & 3.236 & 0.014 \\
\hline
\end{tabular}

a. Dependent variable:TOPRAYSOLAR.

Table 5 is the parameter estimation result of the linear regression of one-variable model, the result shows that constant is 5.822, regression coefficient is 0.829 , the corresponding $\mathrm{t}$ statistic value is 3.236 , the corresponding $\mathrm{P}$ value is 0.014 , less than 0.05 , under the circumstance of $5 \%$ significance level,the regression coefficient of the model apparently pass the significance test. In conclusion, the model has ideal effect. In the end, model expression can be written as: $y=5.822+0.829 * x$

The stock price of the new energy and traditional energy presents obvious convergence relationship. Similarly, Asymmetric BEKK and Asymmetric DCC model also provides a evidence that new energy stock market in China and the international crude oil market exist volatility spillover and asset price fluctuations asymmetrically, for example, two asset price fluctuations is asymmetry on its variance, that is with respect to the positive impact on its earnings, the negative impact is much more bigger on its earnings volatility. The short-term impact of new energy company stock prices has obvious volatility spillover effect on WTI crude oil futures market, which depend on the symbols of two kinds of asset price shocks. From the point of long-term volatility of asset prices, 
there are bidirectional volatility spillover effect between two markets, and the changes of covariance and correlation coefficient between two markets is also associated with two kinds of asset price shocks symbols.

\subsection{Analysis of the Correlation in New Energy Industry's Sub-Professions}

\subsubsection{Import the Stock History Data}

We use the "Tong Hua Shun" software to derive the stocks history data of the two representatives in the new energy industry's sub-professions. In this thesis, we take "TOPRAYSOLAR" and "Goldwind Science\&Technology" as examples, the two stocks are selected the quarterly closing price from 1th January 2014 to 31th March 2016, and then consolidate it to the form of Excel to import into SPSS, in which the date, closing price and the residual error must be included.

Table 6. The stocks history data of "TOPRAYSOLAR" and "Goldwind Science \& Technology"

\begin{tabular}{ccc}
\hline Date & TOPRAYSOLAR closing price & Goldwind Science \& Technology closing price \\
\hline the First quarter of 2016 & 8.87 & 16.42 \\
the Forth quarter of 2015 & 10.99 & 22.79 \\
the Third quarter of 2015 & 7.92 & 13.51 \\
the Second quarter of 2015 & 12.78 & 19.47 \\
the First quarter of 2015 & 13.23 & 19.06 \\
the Forth quarter of 2014 & 9.34 & 14.13 \\
the Third quarter of 2014 & 11.49 & 11.7 \\
the Second quarter of 2014 & 9.99 & 9.49 \\
the First quarter of 2014 & 9.72 & 9.39 \\
\hline
\end{tabular}

\subsubsection{The correlation analysis}

We use SPSS software to carry on the "TOPRAYSOLAR" and "Goldwind Science \& Technology" correlation analysis. But before jumping ahead into correlation analysis, first of all we need to make a scatter plot between the two variables, judging whether it has linear relation between the two from the subjective, as shown in Figure 2.

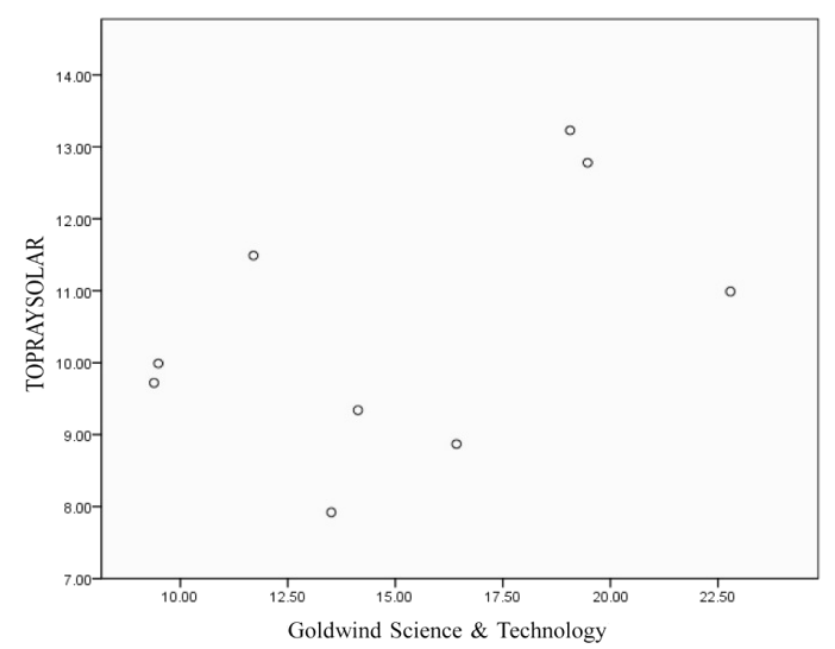

Figure 2. Scatter plot between the two variables

The Figure 2 shows there is a certain relationship between the two variables,In particular with the increase of "Goldwind Science \& Technology" stock price, the price of "TOPRAYSOLAR" is also increasing, however, as to how relevant one stock is to the other, judging from subjective can not be absolute correct, so we need to take things to a next level to calculate the correlation coefficient between "Goldwind Science \& Technology" and "TOPRAYSOLAR", to determine the correlation degree between the two variables.

The calculated correlation coefficient and inspection is as shown in Table 7. 
Table 7. Pearson correlation coefficients

\begin{tabular}{cccc}
\hline & & TOPRAYSOLAR & Goldwind Science\&Technology \\
\hline & Pearson correlation coefficients & 1 & 0.474 \\
TOPRAYSOLAR & Statistical significance & & 0.198 \\
& N & 9 & 9 \\
Goldwind Science \& Technology & Pearson correlation coefficients & 0.474 & 1 \\
& Statistical significance & 0.198 & 9 \\
\hline
\end{tabular}

*. Significant correlation at level 0.05 .

From Table 7, we can get that the Pearson correlation coefficient between "Goldwind Science \& Technology" and "TOPRAYSOLAR" is 0.474 , which means a positive correlation between the two stock, as one stock price growing, the other one grows with it. As we can see from the $\mathrm{P}$ value of the significance test results, $\mathrm{P}$ value is 0.198 , clearly more than 0.05 , under the circumstances of $5 \%$ significance level, the two variables fail to pass the test of significance,therefore, to further find out the relationship between the two stock, we continue to use the regression analysis to check out if it can pass a series of test.

\subsubsection{The Regression Analysis}

To reinforce the stock price change of "TOPRAYSOLAR", to find out how it affected by other factors, "TOPRAYSOLAR" is defined as the dependent variable (y), while "Goldwind Science\&Technology" is defined as the independent variable (x), establishing the linear regression model of one-variable between the two.

Table 8. Model summary

\begin{tabular}{cccccc}
\hline Model & R & R square & Adjusted R square & standard error of estimate & Durbin-Watson \\
\hline 1 & $0.474^{\mathrm{a}}$ & 0.225 & 0.114 & 1.67730 & 2.580 \\
\hline
\end{tabular}

a. Independent variable:Goldwind Science \& Technology.

b. Dependent variable:TOPRAYSOLAR.

The Table 8 shows that $\mathrm{R}$ square value is 0.225 , the adjusted $\mathrm{R}$ square is 0.114 , meaning the degree of fitting for the model is $22.5 \%$, the adjusted degree of fitting for the model is $11.4 \%$, illustrating the model fitting is not good to a certain extent .

Table 9. Analysis of variance

\begin{tabular}{llccccc}
\hline & Model & Sum of Squares & df & Mean square & F & Sig. \\
\hline \multirow{2}{*}{1} & Regression & 5.702 & 1 & 5.702 & 2.027 & $0.198^{\mathrm{b}}$ \\
& Residual error & 19.693 & 7 & 2.813 & & \\
& Final tota & 25.396 & 8 & & & \\
\hline
\end{tabular}

a. Dependent variable:TOPRAYSOLAR.

b. Independent variable:Goldwind Science \& Technology.

Table 9 is the test results of variance analysis for the model significance, what can be seen from the table is that the $\mathrm{F}$ statistic value is 2.027 , the corresponding $\mathrm{P}$ value is 0.198 , which is more than 0.05 , under the circumstance of $5 \%$ significance level, the model fail to pass the significance test.

Table 10. Estimation on varying coeffcient models

\begin{tabular}{|c|c|c|c|c|c|c|}
\hline & \multirow{2}{*}{ Model } & \multicolumn{2}{|c|}{ Unstandardized Coefficients } & \multirow{2}{*}{$\frac{\text { Standardized Coefficients }}{\text { Beta }}$} & \multirow{2}{*}{$\mathrm{t}$} & \multirow{2}{*}{ Sig. } \\
\hline & & $\mathrm{B}$ & Standard error & & & \\
\hline \multirow{2}{*}{1} & (Constant) & 7.752 & 1.997 & & 3.883 & 0.006 \\
\hline & TOPRAYSOLAR & 0.181 & 0.127 & 0.474 & 1.424 & 0.198 \\
\hline
\end{tabular}

a. Dependent variable:TOPRAYSOLAR.

Table 5 is the parameter estimation result of the linear regression of one-variable model, the result shows that 
constant is 7.752 , regression coefficient is 0.181 , the corresponding $\mathrm{t}$ statistic value is 1.424 , the corresponding $\mathrm{P}$ value is 0.198 , larger than 0.05 , under the circumstance of $5 \%$ significance level,the regression coefficient of the model apparently fail to pass the significance test. In conclusion, the effect of the model is not ideal.

To sum up, "TOPRAYSOLAR" and "Goldwind Science \& Technology" has no significant linear correlation, setting up the regression model is unreasonable, so we get a conclusion that there are no correlation relationship in new energy industry's sub-professions. From the impact of product market competition has on the enterprise capital structure, the new energy industry's sub-professions preference ranking is nuclear power, wind energy, biomass energy and solar energy. From the impact of product market environment has on the enterprise capital structure, the macro competition environment and medium competition environment both can affect the enterprise capital structure, but since the product market competition environment factors is difficult to quantify, especially it is difficult to find a suitable indicators to describe the macro competition environment, quantitative analysis can hardly be completed.

\section{Conclusion}

Most empirical study on the energy industry in China is based on the listed company, lacking of comparative analysis. So in this thesis, we carry out research on the relativity between new energy and traditional energy industry, and also in the new energy industry's sub-professions, which has a practical and innovative significance. Research on the correlation of new energy and traditional energy stock can broaden the investment channels and types. Research on the new energy industry's sub-professions can get to know development situation of each energy industry.

In this thesis, we analyze the new energy stock and the traditional energy stock, selecting the stock price model from 2014 to 2016, using SPSS software to evaluate the stock investment value in the energy industry, coming to the conclusion combined with the data analysis results. The research results show that the correlation relationship between new energy and traditional energy stock price is high, but there is no obvious convergence relation in the new energy industry's sub-professions. This conclusion aims at the deficiency of existing research, hoping to provide the reference for the investors.

\section{References}

Ben, X. (2015). Based on SPSS correlation and regression analysis of stock investment study algorithm. Computer Knowledge and Technology, 18, 88-89.

LingDi, Z., \& LeLe, Z. (2012). China's new energy industry segment stock investment value research based on entropy weight TOPSIS method. Journal of Guangdong College, 6, 75-81.

TianCheng, Q. (2014). Traditional energy and carbon trading price and the new energy price analysis based on VAR and CAPM - GARCH model. Journal of Technology Economy and Management Research, 12, 120-124.

XiaoQian, W., Yu, W., \& DengShi, H. (2012). China new energy company's stock price and the price of crude oil volatility spillover and correlation studies. Management Review, 12, 20-30.

ZhiJian, Z., KaiWen, Y., \& Li, Q. (2015). Correlation study between new energy stocks based on complex $\begin{array}{lllll}\text { networks. Journal of Financial Theory and Practice, 6, 44. } & \text {. }\end{array}$ https://doi.org/10.3969/j.issn.1003-7217.2015.06.008

\section{Copyrights}

Copyright for this article is retained by the author(s), with first publication rights granted to the journal.

This is an open-access article distributed under the terms and conditions of the Creative Commons Attribution license (http://creativecommons.org/licenses/by/4.0/). 